\title{
Interactive Response Technology User Manual
}

National Cancer Institute

\section{Source}

National Cancer Institute. Interactive Response Technology User Manual. NCI

Thesaurus. Code C115540.

Documentation providing operational instructions for the interactive response technology. 